\title{
Renal Dysfunction Is an Independent Risk Factor for Mortality after Liver Resection and the Main Determinant of Outcome in Posthepatectomy Liver Failure
}

\author{
M. G. Wiggans, ${ }^{1,2}$ G. Shahtahmassebi, ${ }^{3}$ M. J. Bowles, ${ }^{1}$ S. Aroori, ${ }^{1}$ and D. A. Stell ${ }^{1,2}$ \\ ${ }^{1}$ Hepatobiliary Surgery, Plymouth Hospitals NHS Trust, Derriford Hospital, Derriford Road, Plymouth, Devon PL6 8DH, UK \\ ${ }^{2}$ Peninsula College of Medicine and Dentistry, University of Exeter and Plymouth University, John Bull Building, Plymouth, \\ Devon PL6 8BU, UK \\ ${ }^{3}$ School of Science and Technology, Nottingham Trent University, Nottingham NG1 4BU, UK
}

Correspondence should be addressed to D. A. Stell; david.stell@nhs.net

Received 23 May 2013; Revised 5 September 2013; Accepted 24 September 2013

Academic Editor: Vito R. Cicinnati

Copyright (C) 2013 M. G. Wiggans et al. This is an open access article distributed under the Creative Commons Attribution License, which permits unrestricted use, distribution, and reproduction in any medium, provided the original work is properly cited.

\begin{abstract}
Introduction. The aim of this study was to assess the interaction of liver and renal dysfunction as risk factors for mortality after liver resection. Materials and Methods. A retrospective analysis of 501 patients undergoing liver resection in a single unit was undertaken. Posthepatectomy liver failure (PHLF) was defined according to the International Study Group of Liver Surgery (ISGLS) definition (assessed on day 5) and renal dysfunction according to RIFLE criteria. 90-day mortality was recorded. Results. Twenty-three patients died within 90 days of surgery (4.6\%). The lowest mortality occurred in patients without evidence of PHLF or renal dysfunction (2.7\%). The mortality rate in patients with isolated PHLF or renal dysfunction was $20 \%$ compared to $45 \%$ in patients with both. Diabetes $(P=0.028)$, renal dysfunction $(P=0.030)$, and PHLF on day $5(P=0.011)$ were independent predictors of 90 -day mortality. Discussion. PHLF and postoperative renal dysfunction are independent predictors of 90-day mortality following liver resection but the predictive value for mortality is significantly higher when failure of both organ systems occurs simultaneously.
\end{abstract}

\section{Introduction}

Despite advances in both operative technique and perioperative care liver resection is associated with mortality rates of 0 to $22 \%$ (median $3.7 \%$ ) and morbidity rates of $12.5 \%$ to $66 \%$ (median $36 \%$ ) [1] including liver $[2,3]$ and renal dysfunction [4]. Liver dysfunction is a major contributor to both morbidity and mortality with an incidence between $1.2 \%$ and $32 \%$ in published series [5-12]. Renal dysfunction has also been shown to be associated with mortality following liver resection [13], with a reported incidence between 5 and $15 \%[4,14]$. Posthepatectomy renal failure may occur in conjunction with liver failure when maldistributive circulatory changes occur causing intravascular hypovolaemia $[4,15]$ but is also related to operative stress and blood loss $[16,17]$.

Postoperative liver dysfunction has been defined by the "50-50 criteria" as a prothrombin index of less than $50 \%$ (mean normal prothrombin time (PT) divided by patient's observed PT) and a serum bilirubin of $>50 \mu \mathrm{mol} / \mathrm{L}$ on the fifth postoperative day, which has been shown to predict liver failure and death after hepatectomy [2]. More recently posthepatectomy liver failure (PHLF) has been defined by the International Study Group of Liver Surgery (ISGLS) as a postoperatively acquired deterioration in the ability of the liver to maintain its synthetic, excretory, and detoxifying functions, characterized by an increased INR (or need of clotting factors to maintain normal INR) and hyperbilirubinaemia on or after postoperative day five [18]. The ability of this newer definition of PHLF, using lower measures of dysfunction, to predict mortality has not been thoroughly assessed.

The aim of this study was to assess the utility of the ISGLS definition of PHLF on postoperative day 5 as a predictor of mortality and to determine the interaction of liver and renal dysfunction in predicting 90-day mortality after liver resection. 


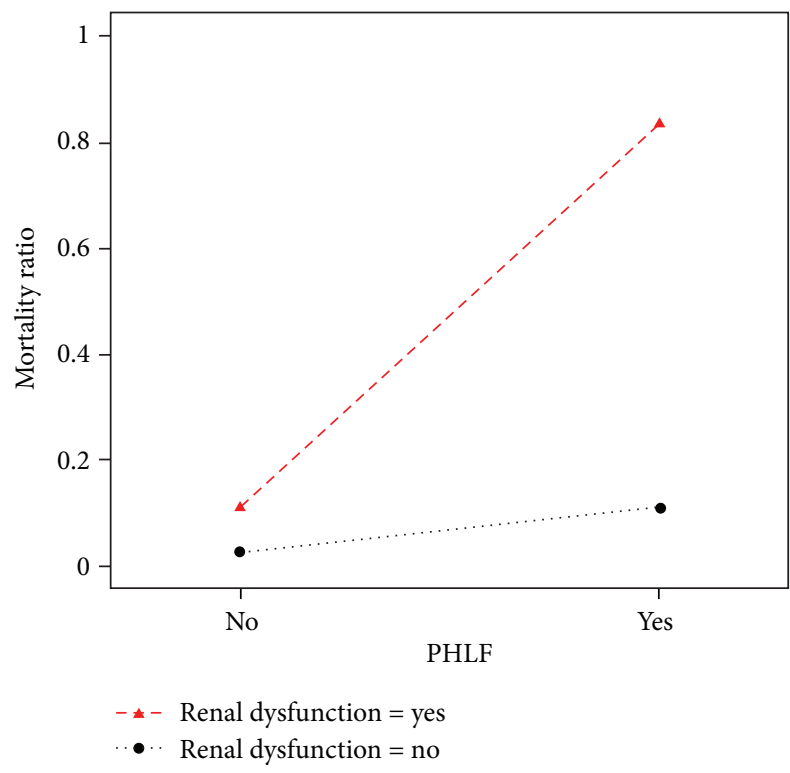

FIGURE 1: Mortality ratio of combined liver and renal dysfunction in 495 patients undergoing liver resection.

\section{Materials and Methods}

A retrospective analysis of a prospectively maintained database of all patients undergoing liver resection in this unit between July 2005 and September 2012 was undertaken. Five hundred and one patients were studied. Patient characteristics, laboratory data, and intraoperative details were retrieved. Liver resections were defined according to the Brisbane classification [19] and undertaken using standard techniques. Prior to resection the operating surgeon makes a visual assessment of the condition of the liver parenchyma and records this as normal or abnormal. Hepatic inflow occlusion was used in a minority of cases where there was excessive blood loss. The POSSUM scoring system was used to calculate the preoperative physiological risk score [20].

All patients were followed up for a minimum of 90 days and mortality was recorded along with details of the cause of death. The cause of death was determined from case-sheet review, radiological and laboratory data, and death certificates. Patients who died with jaundice and/or radiological evidence of ascites and/or encephalopathy in the absence of any other clear diagnosis were determined to have died of liver failure. Patients who died within 24 hours of surgery were excluded from further analysis as these deaths were most likely due to perioperative complications. Patients were also excluded if no postoperative blood tests were available.

Serum biochemistry tests and coagulation assays were performed on patients in the first 24 postoperative hours and the tests repeated according to clinical course. The peak measurement of bilirubin, prothrombin time (PT), and creatinine were recorded and used for analysis and patients with PHLF were identified as having an increased PT and serum bilirubin on postoperative day five according to the ISGLS definition [18]. In patients with preoperatively increased PT or serum bilirubin concentration PHLF was defined as an
TABLE 1: Preoperative and intraoperative characteristics of 501 patients undergoing hepatic resection.

\begin{tabular}{lcc}
\hline$n=501$ & $\begin{array}{c}\text { Median } \\
\text { (range) }\end{array}$ & Count (\%) \\
\hline Age & $65(21-90)$ & \\
Gender & $223(45)$ \\
Female & $278(55)$ \\
Male & \\
Indication for surgery & $46(9)$ \\
Benign & \\
Primary & $39(8)$ \\
$\quad$ Hepatocellular carcinoma & $31(6)$ \\
$\quad$ Cholangiocarcinoma & \\
$\quad$ Others & & $28(6)$
\end{tabular}

Secondary

Colorectal metastases

Other metastases

Liver directed chemotherapy

Yes

No

Diabetes

Yes

No

BMI

$26(16-54)$

ASA Grade

1

2

3

4

Not recorded

$1(0.2)$

Physiologic risk score

$16(12-32)$

Operative risk score

$24(14-35)$

Estimated P-POSSUM mortality (\%)

$7.7(0.9-69.3)$

Confirmed fibrosis/cirrhosis

Yes

No

479 (96)

Preoperative bilirubin $(\mu \mathrm{mol} / \mathrm{L})$

Preoperative haemoglobin (g/dL)

$9(2-162)$

13.2

(8.6-17.0)

Preoperative white cell count (/L)

Preoperative albumin (g/L)

$6.9(2.7-25.0)$

44 (24-53)

Preoperative alkaline phosphatase $(\mathrm{U} / \mathrm{L})$

$95(34-1190)$

Preoperative creatinine $(\mu \mathrm{mol} / \mathrm{L})$

$78(40-430)$

Preoperative glomerular filtration rate (GFR)

$>90 \mathrm{~mL} / \mathrm{min}$ 
TABle 1: Continued.

\begin{tabular}{|c|c|c|}
\hline$n=501$ & $\begin{array}{l}\text { Median } \\
\text { (range) }\end{array}$ & Count (\%) \\
\hline$<90 \mathrm{~mL} / \mathrm{min}$ & & $326(65)$ \\
\hline Not measured & & $12(2)$ \\
\hline $\begin{array}{l}\text { Preoperative neutrophil lymphocyte } \\
\text { ratio (NLR) }\end{array}$ & $2.5(0.3-17.3)$ & \\
\hline \multicolumn{3}{|l|}{ NLR > 5} \\
\hline Yes & & $59(12)$ \\
\hline No & & $442(88)$ \\
\hline \multicolumn{3}{|l|}{ Open or laparoscopic approach } \\
\hline Open & & $453(90)$ \\
\hline Laparoscopic & & $48(10)$ \\
\hline \multicolumn{3}{|l|}{$\begin{array}{l}\text { Radio frequency ablation (RFA) } \\
\text { included }\end{array}$} \\
\hline Yes & & $23(5)$ \\
\hline No & & $478(95)$ \\
\hline \multicolumn{3}{|l|}{ Wedge resection included } \\
\hline Yes & & $189(38)$ \\
\hline No & & $312(62)$ \\
\hline \multicolumn{3}{|l|}{ Operation } \\
\hline Right hemihepatectomy & & $173(35)$ \\
\hline Extended right hemihepatectomy & & $34(7)$ \\
\hline Left hemihepatectomy & & $64(13)$ \\
\hline Extended left hemihepatectomy & & $17(3)$ \\
\hline Left lateral sectorectomy & & $48(10)$ \\
\hline Wedge resection only & & $133(27)$ \\
\hline Other & & $32(6)$ \\
\hline \multicolumn{3}{|l|}{ Bile duct reconstruction included } \\
\hline Yes & & $46(9)$ \\
\hline No & & $455(91)$ \\
\hline \multicolumn{3}{|l|}{ Synchronous bowel procedure } \\
\hline Yes & & $23(5)$ \\
\hline No & & $478(95)$ \\
\hline \multicolumn{3}{|l|}{ Operation number } \\
\hline 1st resection & & $465(93)$ \\
\hline 2nd resection & & $31(6)$ \\
\hline 3rd resection & & $5(1)$ \\
\hline Number of segments resected & $4(1-6)$ & \\
\hline Number of procedures & $1(1-10)$ & \\
\hline \multicolumn{3}{|l|}{$\begin{array}{l}\text { Surgeon's assessment of liver } \\
\text { parenchyma }\end{array}$} \\
\hline Normal & & $323(64)$ \\
\hline Abnormal & & $171(34)$ \\
\hline Not recorded & & $7(1)$ \\
\hline Blood loss & & \\
\hline
\end{tabular}

TABLE 1: Continued.

\begin{tabular}{lcc}
\hline$n=501$ & $\begin{array}{c}\text { Median } \\
\text { (range) }\end{array}$ & Count (\%) \\
\hline$<500 \mathrm{~mL}$ & & $246(49)$ \\
$500-999 \mathrm{~mL}$ & & $175(35)$ \\
$\geq 1000 \mathrm{~mL}$ & $76(15)$ \\
Not recorded & & $4(0.8)$ \\
Units transfused & $0(0-26)$ & \\
\hline
\end{tabular}

increasing serum bilirubin concentration and increasing PT on postoperative day 5 compared with the values of the previous day. It was not necessary to administer clotting factors to any surviving patients between postoperative days (POD) 1-5. Renal dysfunction was defined as an increase in serum creatinine of $\geq 1.5$-fold from the preoperative baseline within the first five postoperative days, according to RIFLE criteria [21].

To determine potential associations between patient characteristics, operative factors, and organ dysfunction with 90-day mortality univariate logistic regression or chi-square test at the level of $P<0.25$ [22] was performed, as appropriate. Significant variables in the univariate analysis were included in the multivariate logistic regression model and were considered to be significant if $P<0.05$. Mortality ratios for organ failure were calculated as the proportion of deaths to proportion of survivors. All analyses were carried out using the statistical package R 2.1.14 [23].

\section{Results}

Five hundred one patients were studied. The indications for surgery and preoperative and operative details are shown in Table 1. Two patients who died within 24 hours of surgery were excluded from further analysis. One patient died of heart failure after a partially extended right hepatectomy and one died of biliary sepsis and multiorgan failure following an extended right hepatectomy for hilar cholangiocarcinoma. Details of twenty-one patients (4.6\%) who died within 90 days of surgery are shown in Table 2 . There was no significant difference in the median age of patients who died (71 years) and those who survived (65 years). The median interval to death after surgery was 31 days (7-89 days).

Of the 499 patients studied, blood tests were available in 495 patients (99.2\%). Four patients did not have postoperative blood tests, all of whom had minor resections (fewer than three segments) and none of whom died within the study period and were excluded from analysis. A summary of liver and renal function tests in the whole cohort is shown in Table 3 along with the associated mortality.

PHLF occurred in 31 patients of whom two had preexisting liver failure and 12 had extended resections. Seven patients in this group died within 90 days of surgery. Renal dysfunction also occurred in 31 patients, of whom 11 had extended resections. Seven patients in this group died within 90 days of surgery. In 55 patients with diabetes mellitus renal dysfunction occurred in seven patients (12.7\%) compared to 
TABLE 2: Details of 21 patients who died within 90 days of surgery. (Two patients who died within 24 hours of surgery were excluded.)

\begin{tabular}{|c|c|c|c|c|c|c|c|c|c|}
\hline \multirow{2}{*}{ Cause of death } & \multirow{2}{*}{ Count } & \multicolumn{2}{|c|}{ Gender } & \multirow{2}{*}{ Age } & \multirow{2}{*}{$\begin{array}{c}\text { Right } \\
\text { hepatectomy }\end{array}$} & \multirow{2}{*}{$\begin{array}{c}\text { Extended } \\
\text { right }\end{array}$} & \multirow{2}{*}{$\begin{array}{l}\text { Extended } \\
\text { left }\end{array}$} & \multirow{2}{*}{$\begin{array}{l}\text { Minor } \\
\text { resection }\end{array}$} & \multirow{2}{*}{$\begin{array}{c}\text { Interval to } \\
\text { death (days) }\end{array}$} \\
\hline & & Male & Female & & & & & & \\
\hline Liver failure & 11 & 9 & 2 & $67(58-76)$ & 3 & 7 & 1 & 0 & $31(11-83)$ \\
\hline Malignancy & 4 & 2 & 2 & $58(43-76)$ & 2 & 1 & 0 & 1 & $68.5(14-86)$ \\
\hline Sepsis & 1 & 1 & 0 & 71 & 0 & 1 & 0 & 0 & 15 \\
\hline $\mathrm{PE}$ & 1 & 1 & 0 & 71 & 1 & 0 & 0 & 0 & 7 \\
\hline Anastomotic leak & 1 & 1 & 0 & 80 & 0 & 0 & 0 & 1 & 8 \\
\hline Peptic ulcer & 1 & 0 & 1 & 81 & 1 & 0 & 0 & 0 & 22 \\
\hline $\begin{array}{l}\text { Strangulated } \\
\text { hernia }\end{array}$ & 1 & 1 & 0 & 76 & 0 & 0 & 0 & 1 & 89 \\
\hline Peritonitis & 1 & 1 & 0 & 76 & 0 & 0 & 0 & 1 & 70 \\
\hline
\end{tabular}

TABLe 3: Postoperative liver and renal dysfunction in 495 patients undergoing hepatic resection (blood tests not performed in four patients).

\begin{tabular}{lccc}
\hline $\begin{array}{l}\text { Laboratory } \\
\text { parameters at day } 5 \\
(n=495)\end{array}$ & Count (\%) & $\begin{array}{c}\text { 90-day } \\
\text { mortality } \\
(\%)\end{array}$ & $\begin{array}{c}\text { Death due to } \\
\text { liver failure }\end{array}$ \\
\hline $\begin{array}{l}\text { No PHLF or renal } \\
\text { dysfunction }\end{array}$ & $444(89.7)$ & $12(2.7)$ & 4 \\
$\begin{array}{l}\text { PHLF alone } \\
\text { Renal dysfunction } \\
\text { lone }\end{array}$ & $20(4.0)$ & $2(10)$ & 2 \\
$\begin{array}{l}\text { Renal dysfunction } \\
\text { plus PHLF }\end{array}$ & $11(2.2)$ & $5(45.5)$ & 2 \\
\hline
\end{tabular}

24 of 440 patients without diabetes $(5.5 \%)(P=0.067)$. No patient with diabetes and normal preoperative renal function $(n=12)$ developed postoperative renal dysfunction compared to seven of 43 diabetic patients with impaired preoperative renal function $(P=0.326)$.

The lowest mortality (2.7\%) occurred in the 444 patients without laboratory evidence of PHLF or renal dysfunction at day five, of whom 12 died, compared to 9 of 51 (17.6\%) patients with either or both of these diagnoses. In the first group four of the twelve deaths were due to liver failure compared to seven of the nine deaths in the group with evidence of organ dysfunction at POD 5.

The mortality rate in patients who fulfilled the criteria for PHLF on POD 5 but did not have renal dysfunction was identical ( 2 of 10 patients) to that of patients with renal dysfunction without PHLF (2 of 10 patients). All four of these patients died of liver failure. Mortality was greatest in the group of eleven patients with both PHLF and renal dysfunction of whom five died. Three of these five patients died of liver failure, one from anastomotic leak, and one from a bleeding peptic ulcer.

Multivariate analysis of potential risk factors for mortality including postoperative organ dysfunction (Table 4) revealed that the only preoperative factor independently associated with 90-day mortality was the presence of diabetes $(P=$ 0.028 ), which more than trebled the risk of 90 -day mortality.
Both PHLF on POD 5 and postoperative renal dysfunction were independently associated with 90-day mortality. PHLF at POD 5 increased the risk of 90-day mortality by a factor of $4.5(P=0.011)$ and renal dysfunction increased the risk by a factor of $3.6(P=0.030)$.

The positive predictive value (PPV) for mortality in patients who fulfilled the criteria for PHLF (including those with and without renal dysfunction) was $22.6 \%$. However within this group the PPV was much lower (10\%) if the criteria for PLF were fulfilled with normal renal function (Table 5). The PPV for mortality of fulfilling the criteria for PHLF with concurrent renal dysfunction was $45 \%$.

The effect of developing renal dysfunction in the context of PHLF is demonstrated by the greater than fourfold increase in mortality ratio (Figure 1).

\section{Discussion}

The principle findings of this study are that PHLF on POD 5 as defined by the ISGLS and postoperative renal dysfunction are independent predictors of 90-day mortality following liver resection. The predictive value for mortality is significantly higher when failure of both organs occurs, with a PPV of $45 \%$ and NPV of $97 \%$. Preoperative diabetes mellitus is also an independent predictor of 90-day mortality.

The 90 -day mortality (4.6\%) in this series is similar to results of other units [1]. An important observation is that half the postoperative deaths in the series occurred between 31 and 90 days after surgery, stressing the importance of reporting 90-day rather than 30-day mortality. Of the 21 postoperative deaths 11 were found to be due to liver failure.

The study confirms the ability of PHLF to predict 90-day mortality. Interestingly however the majority of patients who developed PHLF at POD 5 (24 of 31) recovered whilst six of the eleven patients who died of liver failure did not fulfil the ISGLS definition of PHLF at POD 5. Only one patient in this series fulfilled the " $50-50$ criteria" of postoperative liver dysfunction, who subsequently recovered. Therefore the "5050 " criteria had no value as a predictor of liver failure or mortality in this series with a PPV of zero. In comparison the ISGLS definition of PHLF has lower thresholds for abnormal bilirubin and PT and is a more clinically useful tool for 
TABLE 4: Univariate and multivariate analysis of preoperative and operative factors as well as postoperative blood tests associated with 90-day mortality following liver resection in 495 patients.

\begin{tabular}{|c|c|c|c|c|}
\hline \multirow{2}{*}{$\begin{array}{l}n=495 \\
\text { Factor (preoperative and operative factors and } \\
\text { postoperative blood tests) }\end{array}$} & \multicolumn{2}{|c|}{ Univariate } & \multicolumn{2}{|c|}{ Multivariate } \\
\hline & Coef $(95 \%$ CI $)$ & $P$ value & Coef $(95 \%$ CI $)$ & $P$ value \\
\hline Age & $1.05(1.01-1.10)$ & $0.029^{*}$ & & 0.194 \\
\hline Gender & $2.36(0.91-6.08)$ & $0.077^{*}$ & & 0.196 \\
\hline Pathology & & 0.274 & & \\
\hline Liver directed chemotherapy & & 0.356 & & \\
\hline Diabetic & $3.09(1.16-8.20)$ & $0.024^{*}$ & $3.41(1.14-10.23)$ & $0.028^{* *}$ \\
\hline BMI & & 0.444 & & \\
\hline \multicolumn{5}{|l|}{ ASA grade } \\
\hline 1 versus 2 & $3.02(0.70-13.11)$ & $0.139^{*}$ & & 0.678 \\
\hline 2 versus 3 & & 0.724 & & \\
\hline Physiologic score & $1.12(1.03-1.22)$ & $0.010^{*}$ & & 0.544 \\
\hline Operative score & & 0.303 & & \\
\hline P-POSSUM mortality & $1.04(1.01-1.07)$ & $0.010^{*}$ & & 0.479 \\
\hline Fibrosis/cirrhosis & & 0.986 & & \\
\hline Preoperative bilirubin & $1.01(1.00-1.03)$ & $0.081^{*}$ & & 0.652 \\
\hline Preoperative haemoglobin & $0.71(0.55-0.93)$ & $0.012^{*}$ & & 0.195 \\
\hline Preoperative white cell count & & 0.388 & & \\
\hline Preoperative albumin & $0.90(0.84-0.96)$ & $0.002^{*}$ & & 0.168 \\
\hline Preoperative alkaline phosphatase & & 0.884 & & \\
\hline Preoperative creatinine & $1.01(1.00-1.02)$ & $0.098^{*}$ & & 0.764 \\
\hline Preoperative neutrophil lymphocyte ratio & $1.13(0.98-1.31)$ & $0.086^{*}$ & & 0.366 \\
\hline Preoperative neutrophil lymphocyte ratio $>5$ & $2.18(0.78-6.11)$ & $0.138^{*}$ & & 0.345 \\
\hline Open or laparoscopic resection & & 0.987 & & \\
\hline Radiofrequency ablation (RFA) included & & 0.991 & & \\
\hline Wedge resection included & & 0.588 & & \\
\hline Bile duct reconstruction included & $2.96(1.05-8.39)$ & $0.041^{*}$ & & 0.383 \\
\hline Synchronous bowel procedure & & 0.346 & & \\
\hline Operation number & & 0.549 & & \\
\hline Number of segments resected & $1.59(1.18-2.14)$ & $0.003^{*}$ & & 0.075 \\
\hline Number of procedures & & 0.786 & & \\
\hline Surgeons assessment of liver parenchyma & $2.14(0.92-4.96)$ & $0.076^{*}$ & & 0.494 \\
\hline \multicolumn{5}{|l|}{ Blood loss (mL) } \\
\hline$<500$ versus $>500$ & $2.67(1.27-5.61)$ & $0.009^{*}$ & & 0.716 \\
\hline$>500$ versus $>1000$ & & 0.652 & & \\
\hline Units of red cells transfused & $1.13(1.02-1.26)$ & $0.023^{*}$ & & 0.224 \\
\hline PHLF at POD 5 & $1.02(1.01-1.03)$ & $<0.001^{*}$ & $4.51(1.42-14.40)$ & $0.011^{* *}$ \\
\hline Renal dysfunction (creatinine rise $>1.5 \mathrm{x}$ ) & $1.02(1.01-1.03)$ & $<0.001^{*}$ & $3.63(1.13-11.66)$ & $0.030^{* *}$ \\
\hline
\end{tabular}

${ }^{*}$ Significant at the level of 0.25 for univariate analysis and included in multivariate analysis.

** Significant at the level of 0.05 for multivariate analysis.

the prediction of 90 -day mortality with a PPV of $23 \%$ and NPV 97\%. This is similar to the findings of the only other study to address this issue, which revealed that the PPV and NPV of PHLF were $32 \%$ and $98 \%$, respectively [24]. Simple blood tests therefore have a low positive predictive value for mortality due to liver failure.

Renal dysfunction occurred in $6.3 \%$ of patients which is similar to other published series $[4,14]$. Renal dysfunction 
TABLE 5: Predictive values of PHLF and renal dysfunction within the first five postoperative days in 495 patients undergoing liver resection.

\begin{tabular}{lcc}
\hline & $\begin{array}{c}\text { Positive predictive } \\
\text { value (PPV) }\end{array}$ & $\begin{array}{c}\text { Negative predictive } \\
\text { value (NPV) }\end{array}$ \\
\hline $\begin{array}{l}\text { No PHLF or renal } \\
\text { dysfunction }\end{array}$ & 0.027 & 0.824 \\
$\begin{array}{l}\text { PHLF alone } \\
\begin{array}{l}\text { Renal dysfunction } \\
\text { alone }\end{array}\end{array}$ & 0.1 & 0.970 \\
$\begin{array}{l}\text { PHLF and renal } \\
\text { dysfunction }\end{array}$ & 0.1 & 0.970 \\
\hline
\end{tabular}

following liver resection may occur as a consequence of liver failure and hepatorenal syndrome but may also result from hypovolaemia or damage from inflammatory mediators during surgery [4]. This occurs more commonly in elderly patients with atherosclerosis or hypertension [15]. These mechanisms of renal dysfunction may occur simultaneously. The use of low central venous pressure (CVP) during resection may also increase the risk of postoperative renal dysfunction $[25,26]$. The results of this study demonstrate that isolated renal dysfunction is a significant risk factor for mortality independent of the development of PHLF. Interestingly the two patients with isolated renal dysfunction in the first five postoperative days subsequently died of liver failure. This may be attributed to renal dysfunction delaying the onset of hepatic regeneration [27]. The most marked mortality effect of renal dysfunction was seen in conjunction with PHLF, where the mortality rate increased by a factor of four. Therefore, although the ISGLS definition of PHLF is able to predict mortality due to liver failure the development of renal dysfunction in this context is the single most important predictive factor.

The finding of the significance of diabetes as a risk factor for postoperative mortality confirms earlier findings [28]. Insulin is important for hepatic function and regeneration [29] and diabetes is also a risk factor for the development of nonalcoholic fatty liver disease and cirrhosis [30] which may lead to higher rates of PHLF [31]. Diabetic nephropathy is also a major cause of renal dysfunction [32].

In conclusion we have demonstrated that PHLF as defined by the ISGLS on postoperative day five and postoperative renal dysfunction are able to predict 90 -day mortality following liver resection, although most patients fulfilling these criteria of organ dysfunction will recover. In addition many patients will succumb to liver failure without fulfilling the PHLF criteria in the early postoperative period. The combination of these two markers of organ dysfunction is the best early predictor of mortality following liver resection and we suggest that PHLF and postoperative renal dysfunction should be used in conjunction when predicting mortality after liver resection.

\section{References}

[1] C. D. Mann, T. Palser, C. D. Briggs et al., "A review of factors predicting perioperative death and early outcome in hepatopancreaticobiliary cancer surgery," $H P B$, vol. 12, no. 6, pp. 380-388, 2010.

[2] S. Balzan, J. Belghiti, O. Farges et al., "The "50-50 criteria" on postoperative day 5: an accurate predictor of liver failure and death after hepatectomy," Annals of Surgery, vol. 242, no. 6, pp. 824-829, 2005.

[3] T. Schreckenbach, J. Liese, W. O. Bechstein, and C. Moench, "Posthepatectomy liver failure," Digestive Surgery, vol. 29, no. 1, pp. 79-85, 2012.

[4] F. Saner, "Kidney failure following liver resection," Transplantation Proceedings, vol. 40, no. 4, pp. 1221-1224, 2008.

[5] M. A. J. van den Broek, S. W. M. O. Damink, C. H. C. Dejong et al., "Liver failure after partial hepatic resection: definition, pathophysiology, risk factors and treatment," Liver International, vol. 28, no. 6, pp. 767-780, 2008.

[6] O. Farges, B. Malassagne, J. F. Flejou, S. Balzan, A. Sauvanet, and J. Belghiti, "Risk of major liver resection in patients with underlying chronic liver disease: a reappraisal," Annals of Surgery, vol. 229, no. 2, pp. 210-215, 1999.

[7] J. Belghiti, K. Hiramatsu, S. Benoist, P. P. Massault, A. Sauvanet, and O. Farges, "Seven hundred forty-seven hepatectomies in the 1990s: an update to evaluate the actual risk of liver resection," Journal of the American College of Surgeons, vol. 191, no. 1, pp. 38-46, 2000.

[8] A. Cucchetti, G. Ercolani, M. Vivarelli et al., "Impact of model for end-stage liver disease (MELD) score on prognosis after hepatectomy for hepatocellular carcinoma on cirrhosis," Liver Transplantation, vol. 12, no. 6, pp. 966-971, 2006.

[9] S. Dinant, W. de Graaf, B. J. Verwer et al., "Risk assessment of posthepatectomy liver failure using hepatobiliary scintigraphy and CT volumetry," Journal of Nuclear Medicine, vol. 48, no. 5, pp. 685-692, 2007.

[10] M. Karoui, C. Penna, M. Amin-Hashem et al., "Influence of preoperative chemotherapy on the risk of major hepatectomy for colorectal liver metastases," Annals of Surgery, vol. 243, no. 1, pp. 1-7, 2006.

[11] L. McCormack, H. Petrowsky, W. Jochum, K. Furrer, and P. A. Clavien, "Hepatic steatosis is a risk factor for postoperative complications after major hepatectomy: a matched case-control study," Annals of Surgery, vol. 245, no. 6, pp. 923-930, 2007.

[12] J. T. Mullen, D. Ribero, S. K. Reddy et al., "Hepatic insufficiency and mortality in 1,059 noncirrhotic patients undergoing major hepatectomy," Journal of the American College of Surgeons, vol. 204, no. 5, pp. 854-862, 2007.

[13] K. Slankamenac, S. Breitenstein, U. Held, B. Beck-Schimmer, M. A. Puhan, and P. Clavien, "Development and validation of a prediction score for postoperative acute renal failure following liver resection," Annals of Surgery, vol. 250, no. 5, pp. 720-727, 2009.

[14] T. Armstrong, F. K. S. Welsh, J. Wells, K. Chandrakumaran, T. G. John, and M. Rees, "The impact of pre-operative serum creatinine on short-term outcomes after liver resection," $H P B$, vol. 11, no. 8, pp. 622-628, 2009.

[15] J. G. Abuelo, "Normotensive ischemic acute renal failure," The New England Journal of Medicine, vol. 357, no. 8, pp. 797-805, 2007.

[16] W. R. Jarnagin, M. Gonen, Y. Fong et al., "Improvement in perioperative outcome after hepatic resection: analysis of 1,803 consecutive cases over the past decade," Annals of Surgery, vol. 236, no. 4, pp. 397-407, 2002. 
[17] H. Imamura, Y. Seyama, N. Kokudo et al., "One thousand fiftysix hepatectomies without mortality in 8 years," Archives of Surgery, vol. 138, no. 11, pp. 1198-1206, 2003.

[18] N. N. Rahbari, O. J. Garden, R. Padbury et al., "Posthepatectomy liver failure: a definition and grading by the international study group of liver surgery (ISGLS)," Surgery, vol. 149, no. 5, pp. 713724, 2011.

[19] J. Belghiti, P. A. Clavien, E. Gadzijev et al., "The Brisbane 2000 terminology of liver anatomy and resections," $H P B$, vol. 2, no. 3 , pp. 333-339, 2000.

[20] G. P. Copeland, D. Jones, and M. Walters, "POSSUM: a scoring system for surgical audit," The British Journal of Surgery, vol. 78, no. 3, pp. 355-360, 1991.

[21] R. Bellomo, C. Ronco, J. A. Kellum, R. L. Mehta, and P. Palevsky, "Acute renal failure-definition, outcome measures, animal models, fluid therapy and information technology needs: the second international consensus conference of the acute dialysis quality initiative (ADQI) group," Critical Care, vol. 8, no. 4, pp. R204-R212, 2004.

[22] A. Agresti, An Introduction to Categorical Data Analysis, John Wiley \& Sons, Hoboken, NJ, USA, 2nd edition, 2002.

[23] “'R'-project for statistical computing," 2011, http://www.rproject.org/.

[24] N. N. Rahbari, C. Reissfelder, M. Koch et al., "The predictive value of postoperative clinical risk scores for outcome after hepatic resection: a validation analysis in 807 patients," Annals of Surgical Oncology, vol. 18, no. 13, pp. 3640-3649, 2011.

[25] R. M. Jones, C. E. Moulton, and K. J. Hardy, "Central venous pressure and its effect on blood loss during liver resection," The British Journal of Surgery, vol. 85, no. 8, pp. 1058-1060, 1998.

[26] R. A. Schroeder, B. H. Collins, E. Tuttle-Newhall et al., "Intraoperative fluid management during orthotopic liver transplantation," Journal of Cardiothoracic and Vascular Anesthesia, vol. 18, no. 4, pp. 438-441, 2004.

[27] T. Kawai, Y. Yokoyama, M. Nagino, T. Kitagawa, and Y. Nimura, "Is there any effect of renal failure on the hepatic regeneration capacity following partial hepatectomy in rats?" Biochemical and Biophysical Research Communications, vol. 352, no. 2, pp. 311-316, 2007.

[28] S. A. Little, W. R. Jarnagin, R. P. DeMatteo, L. H. Blumgart, and Y. Fong, "Diabetes is associated with increased perioperative mortality but equivalent long-term outcome after hepatic resection for colorectal cancer," Journal of Gastrointestinal Surgery, vol. 6, no. 1, pp. 88-94, 2002.

[29] G. K. Michalopoulos, "Liver regeneration," Journal of Cellular Physiology, vol. 213, no. 2, pp. 286-300, 2007.

[30] I. R. Wanless and J. S. Lentz, "Fatty liver hepatitis (steatohepatitis) and obesity: an autopsy study with analysis of risk factors," Hepatology, vol. 12, no. 5, pp. 1106-1110, 1990.

[31] K. E. Behrns, G. G. Tsiotos, N. F. DeSouza, M. K. Krishna, J. Ludwig, and D. M. Nagorney, "Hepatic steatosis as a potential risk factor for major hepatic resection," Journal of Gastrointestinal Surgery, vol. 2, no. 3, pp. 292-298, 1998.

[32] Y. M. Sun, Y. Su, J. Li, and L. F. Wang, "Recent advances in understanding the biochemical and molecular mechanism of diabetic nephropathy," Biochemical and Biophysical Research Communications, vol. 433, no. 4, pp. 359-361, 2013. 


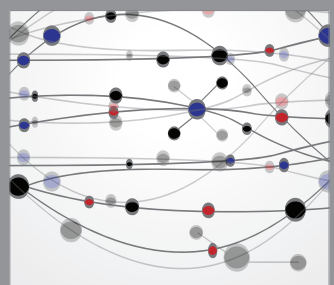

The Scientific World Journal
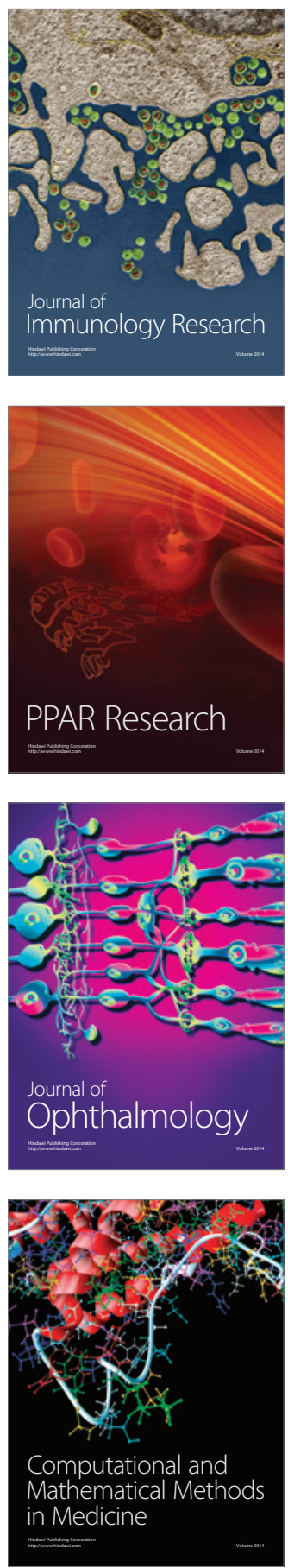

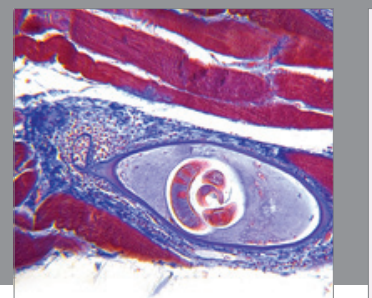

Gastroenterology

Research and Practice
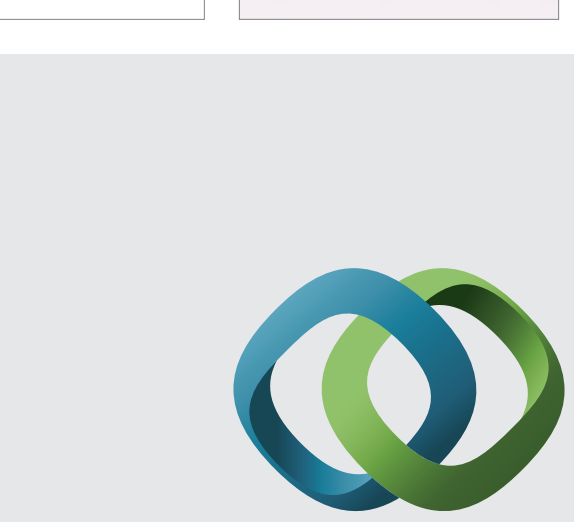

\section{Hindawi}

Submit your manuscripts at

http://www.hindawi.com
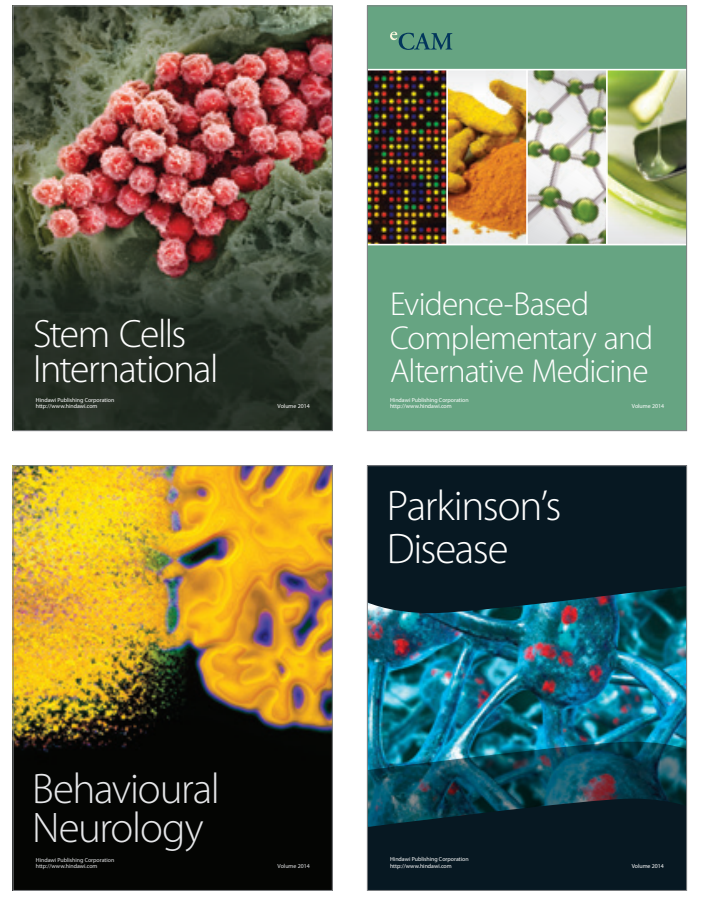
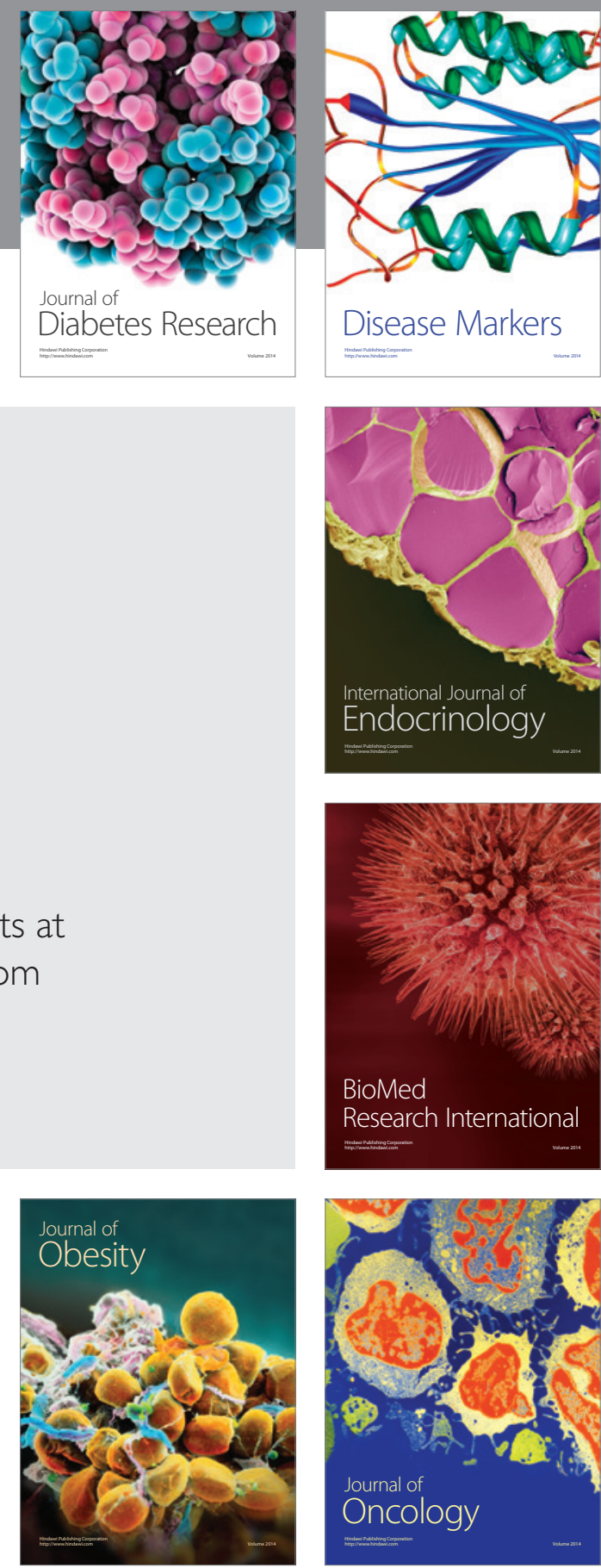

Disease Markers
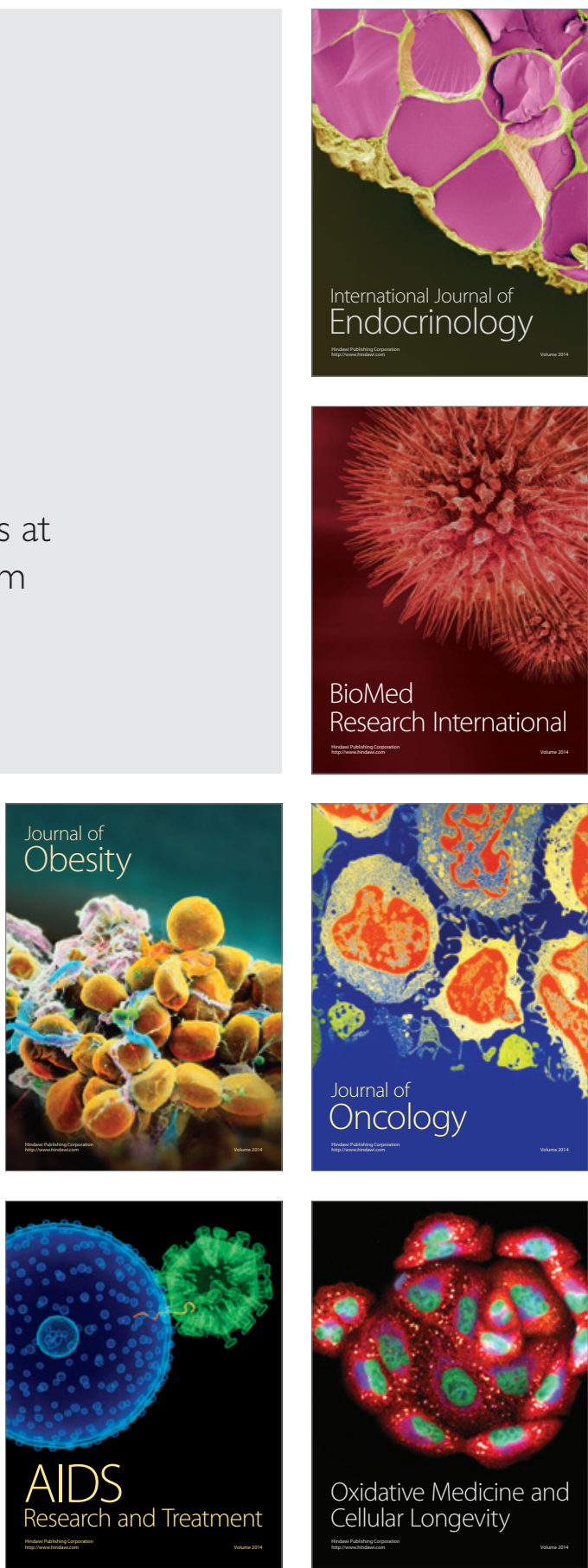